\title{
Development of Rough Surface and Deformation Mechanisms of Poly(ethylene terephthalate) Films
}

\author{
Akira TANAKA,${ }^{*}$ Hikoichi NAgANO, and Shigeharu ONOGI ${ }^{* *}$ \\ Department of Polymer Chemistry, Faculty of Engineering, \\ Kyoto University, Kyoto 606, Japan
}

(Received February 4, 1988)

\begin{abstract}
A rough surface was developed on films when precrystallized poly(ethylene terephthalate) films were drawn. The effects of the crystallization temperature and drawing temperature on the development of rough surface were investigated. The morphological features were examined by POM, SEM, and LS. It was found that a lump in rough surfaces consists of several spherulites which remain undeformed in the drawing process. The size of the spherulites and the degree of the crystallinity, in other words, the degree of the volume filling of the spherulites in the film specimen is an important factor in the development of a rough surface. Rough surfaces were also obtained by biaxial elongation.

KEY WORDS Rough Surface / Deformation Mechanisms / Spherulites /

Crystallization / Drawing / Poly(ethylene terephthalate) /
\end{abstract}

Poly(ethylene terephthalate) (designated as PET hereafter) is one of the more useful polymers in the form of drawn fiber and film. Extensive work has thus been reported on the structure $^{1-4}$ and mechanical properties ${ }^{5-7}$ of drawn PET. However, to our knowledge, there have been no reports on the development of the rough surface on PET films only by heattreatment and drawing.

From a practical point of view, a rough surface is an interesting property. A rough surface affords characteristics such as opaqueness, print ability, and surface bulkiness to polymeric films or fibers. Polymeric materials, in original form, exhibit water, tear, and electro-conduction resistances. A combination of these characteristics with the rough surface may provide us with utilities such as the socalled 'plastic paper' and insulating paper for electric condenser. The traditional techniques to give a rough surface on a polymeric film are mechanical treatments such as those called 'emboss' and 'sand bluster' or chemical treatment such as chemical etching. The method by heat-treatment and drawing for the development of rough surfaces has some advantages. For example, the additional processes such as mechanical and chemical treatments are not necessary. Furthermore, the use of toxic chemicals is unnecessary.

The development of rough surfaces, on the other hand, is also interesting in the study of deformation mechanisms of polymeric solids. The purpose of this study is to clarify the origin of the rough surface developed by drawing and examine the effects of crystallization temperature and drawing temperature upon the development of rough surface of PET films. The morphological changes with crystallization and drawing were observed by polarized optical microscope (POM), scanning electron microscope (SEM), and light scat-

* To whom correspondence should be addressed.

** Present address: Matsue Technical College, Matsue 690, Japan. 
tering (LS).

\section{EXPERIMENTAL}

The PET used in this study was obtained from Toyobo Co., Ltd. The weight average molecular weight was 37,200 and the ratio of the weight average molecular weight to the number average molecular weight $\bar{M}_{w} / \bar{M}_{n}$ was about 2 . The intrinsic viscosity of the polymer in mixing solvent of phenol and tetrachloroethane $(3: 2)$ at $30^{\circ} \mathrm{C}$ was $0.60 \mathrm{dl} \mathrm{g}^{-1}$.

The shape of rough bumps such as their depth and width was measured by the surface texture and contour measuring instrument, Surfcom-300A (Tokyo Seimitsu Co., Ltd.) as well as by LS, POM, and SEM.

\section{RESULTS AND DISCUSSION}

\section{Effects of Crystallization Temperature and Drawing Temperature}

The as-received PET films were the same isotropic and amorphous ones used in the previous paper. ${ }^{8}$ Films with different degrees of crystallinities $(2-50 \mathrm{wt} \%)$ were prepared by heating the as-received PET films in an oven controlled at various temperatures between 100 and $200^{\circ} \mathrm{C}$ for $15 \mathrm{~min}$. Then these films were uniaxially drawn at $96^{\circ} \mathrm{C}$. The draw ratio was 5 . The density and degree of crystallinity for undrawn and drawn PET films were determined and described in the previous paper. ${ }^{8}$ The development of rough surface was found only on the drawn films initially crystallized at temperatures between 110 and $115^{\circ} \mathrm{C}$. In the case of undrawn films, the higher the crystallization temperature, the greater the opaqueness became. However, in the case of drawn films, the opaqueness was greatest in films initially crystallized at 110 and $115^{\circ} \mathrm{C}$. Other films were very transparent, although the film initially crystallized at $200^{\circ} \mathrm{C}$ was a little opaque.

In order to examine the effect of drawing temperature upon the development of rough surface, the films initially crystallized at $115^{\circ} \mathrm{C}$ for $15 \mathrm{~min}$ were drawn at $80,96,115$, and $135^{\circ} \mathrm{C}$. The draw ratio $(\lambda)$ was 5 . A rough surface was seen on the films drawn at 96 and $115^{\circ} \mathrm{C}$ but not on the films drawn at other temperatures.

Figure 1 shows scanning electron micrographs of the films prepared under different conditions. As shown in the picture (d), the film prepared by drawing at $96^{\circ} \mathrm{C}$ after being crystallized at $115^{\circ} \mathrm{C}$ exhibits many undulations. Picture (f) is the only other picture exhibiting such an undulation.

Figure 2 shows $H_{\mathrm{v}}$-light scattering patterns for various kinds of drawn PET films. In the top row of the figure, the change of LS pattern with the crystallization temperature is demonstrated and in the bottom row that with the drawing temperature is. As is evident from the figure, the $H_{\mathrm{v}}$-light scattering patterns of the drawn films initially crystallized at 120 and $140^{\circ} \mathrm{C}$ exhibit a clover pattern extending in the direction perpendicular to the stretching direction. The extended clover pattern indicates that spherulitic structures are deformed and/or disrupted to a greater or less extent in the drawing process. On the other hand, in the $H_{\mathrm{v}}{ }^{-}$ light scattering patterns of the drawn films initially crystallized at 110 and $115^{\circ} \mathrm{C}$, the skewness (or extension) of four-leaf clover pattern was very little. The little skewness indicates that spherulitic structures remain almost underformed in spite of relatively drastic elongation (draw ratio $(\lambda): 5$ ).

The situation is quite analogous to the case in which film was drawn at different temperatures. That is, the $H_{\mathrm{v}}$-light scattering patterns of the films drawn at 96 and $115^{\circ} \mathrm{C}$ exhibit an unskewed four leaf clover pattern. On the other hand; the $H_{\mathrm{v}}$-light scattering patterns of the films drawn at 80 and $135^{\circ} \mathrm{C}$ exhibit an extended four leaf clover pattern.

From these observations, it was found that a rough surface might result from the spherulitic structures which remain underformed in the drawing process. It was also found that the 


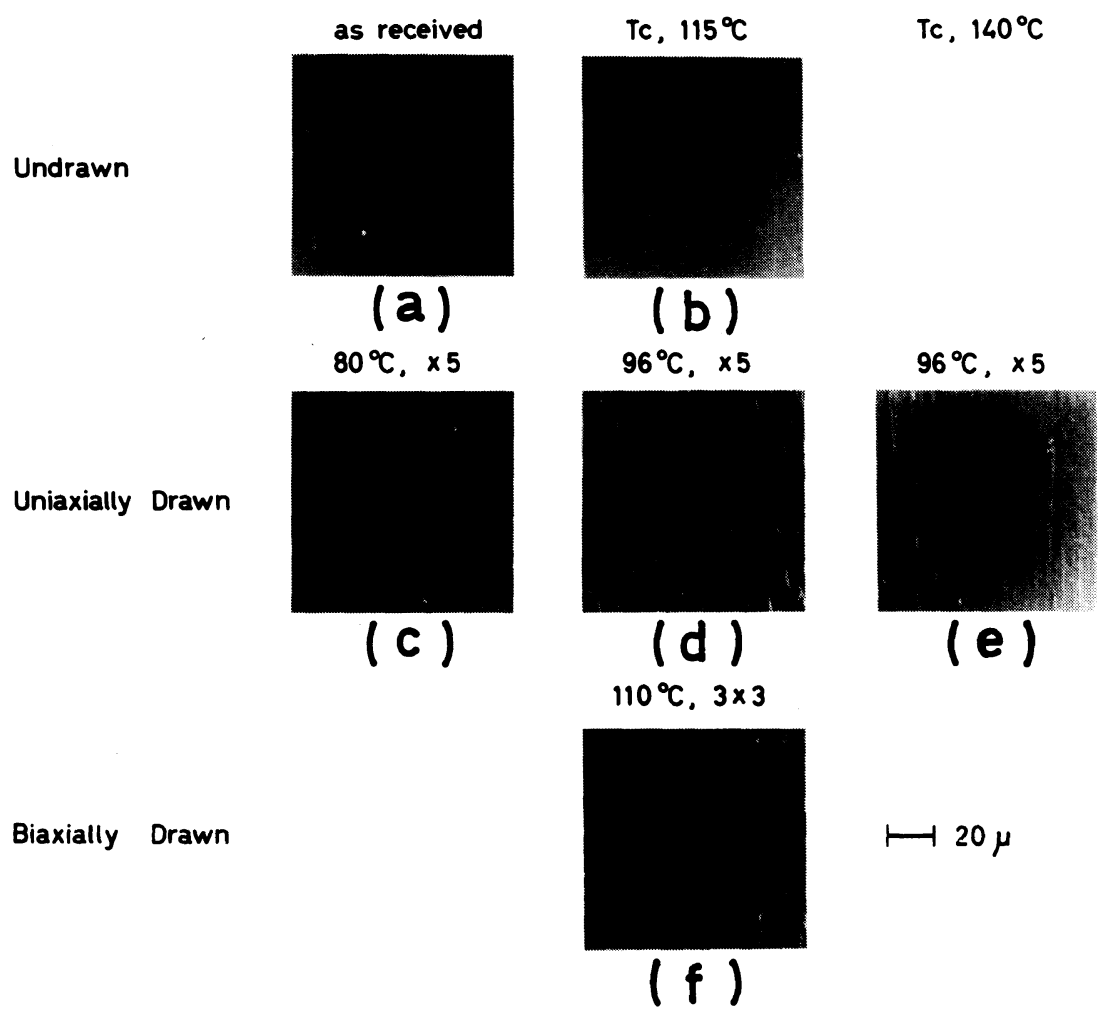

Figure 1. Scanning electron micrographs for several kinds of PET films prepared at different crystallization temperatures $T_{\mathrm{c}}$ and drawing temperatures $T_{\mathrm{d}}$. a) as-received; b) undrawn, $T_{\mathrm{c}}=110^{\circ} \mathrm{C} ; \mathrm{c}$ ) uniaxially drawn, as-received $/ T_{\mathrm{d}}=80^{\circ} \mathrm{C} / \times 5 ;$ d) uniaxially drawn, $T_{\mathrm{c}}=115^{\circ} \mathrm{C} / T_{\mathrm{d}}=96^{\circ} \mathrm{C} / \times 5$; e) uniaxially drawn, $T_{\mathrm{c}}=140^{\circ} \mathrm{C} / T_{\mathrm{d}}=96^{\circ} \mathrm{C} / \times 5 ;$ f) biaxially drawn, $T_{\mathrm{c}}=115^{\circ} \mathrm{C} / T_{\mathrm{d}}=110^{\circ} \mathrm{C} / 3 \times 3$.

temperature ranges of the crystallization and drawing in which the spherulitic structures remain undeformed in the drawing process are rather narrow.

\section{Structure Changes During Drawing Process}

In Figure 3, the stress-strain and birefringence-strain curves at $96^{\circ} \mathrm{C}$ for the undrawn films crystallized at different temperatures for $15 \mathrm{~min}$ are shown. The rate of elongation was $20 \% \mathrm{~min}^{-1}$. For films crystallized at temperatures lower than $100^{\circ} \mathrm{C}$, stress and birefringence hardly increase with increasing strain. This suggests that molecular chains do not orient but slip past one another. For films crystallized at temperatures higher than $120^{\circ} \mathrm{C}$, stress and birefringence increase greatly with increasing strain. The increases in stress and birefringence are not linear with strain, but have a bump (or stepwise increase) which indicates yielding. This yielding must arise from disruption of the spherulitic structure. On the other hand, stress and birefringence of the films crystallized at the intermediate temperatures increase rather linearly with increasing strain.

In Figure 4, the variations of transmittance $T$ with strain for the films crystallized at different temperatures are shown. Light of $400 \mathrm{~nm}$ wavelength was used for the measurement of the transmittance. For films crystallized at temperatures lower than $100^{\circ} \mathrm{C}$, the transmittance is very high in the whole range of strains. For films crystallized at tempera- 


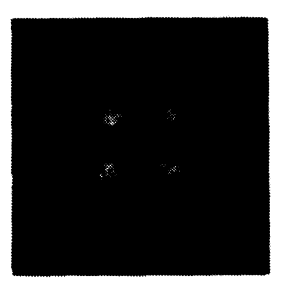

$\begin{array}{rc}\text { Cryst } \operatorname{Temp}\left({ }^{\circ} \mathrm{C}\right) & 110 \\ \text { time }(\mathrm{min}) & 15 \\ \text { Drawn } \operatorname{Temp}\left({ }^{\circ} \mathrm{C}\right) & 96 \\ \text { Draw Ratio } & 5\end{array}$

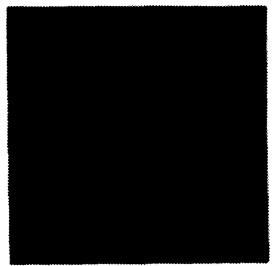

Cryst Temp $\left({ }^{\circ} \mathrm{C}\right)$

time (min)

Drawn Temp $\left({ }^{\circ} \mathrm{C}\right)$

Draw Ratio
115

15

80

5
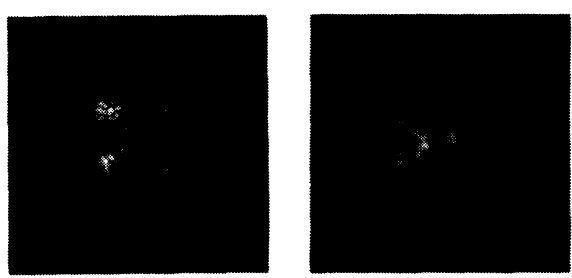

120

15

96

5

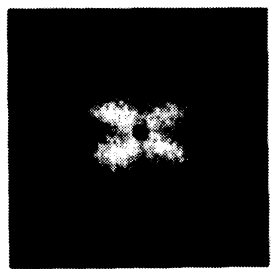

115

15

96

5

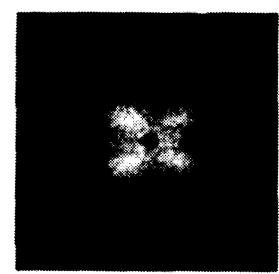

115

15

115

5

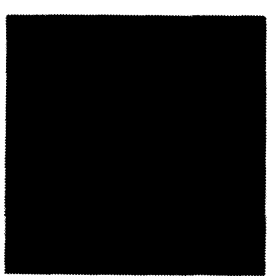

140

15

96

5

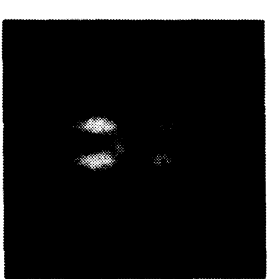

115

15

135

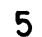

Figure 2. $H_{v}$-light scattering patterns for PET films. Top row demonstrates the change with the crystallization temperature and bottom row the change with the drawing temperature.
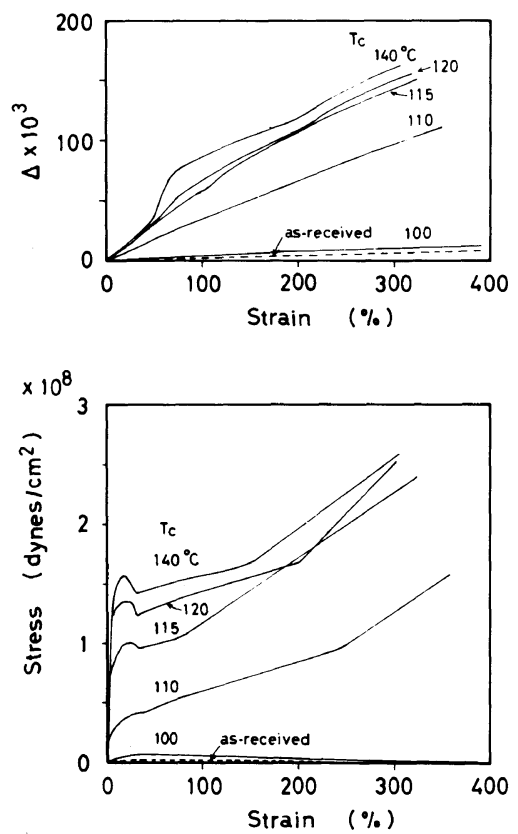

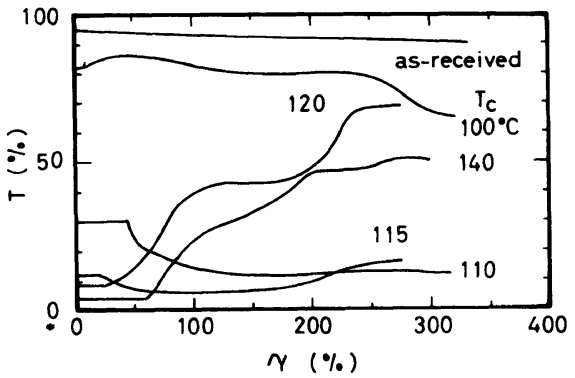

Figure 4. The variation of transmittance $T$ with strain for the films crystallized at different temperatures. Light of $400 \mathrm{~nm}$ wavelength was used. 
Uniaxially Drawn

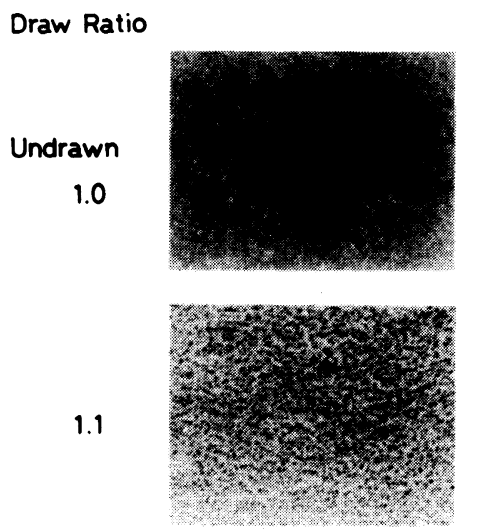

Draw Ratio

1.5

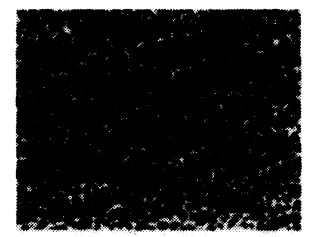

2.0
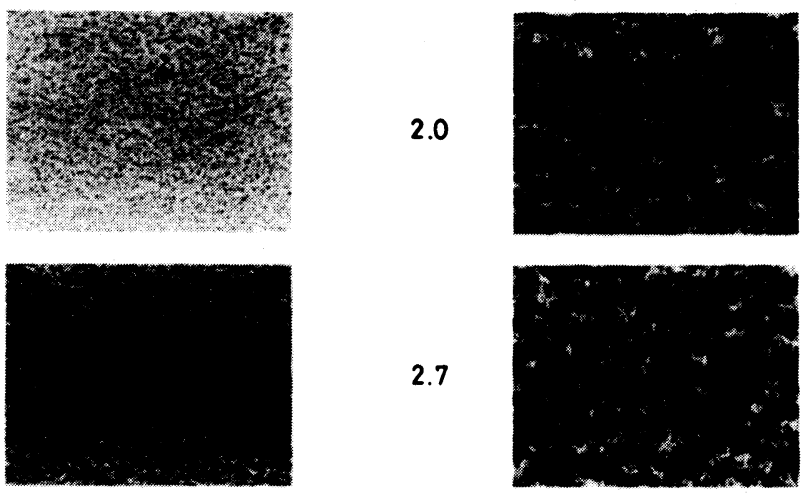

1.3

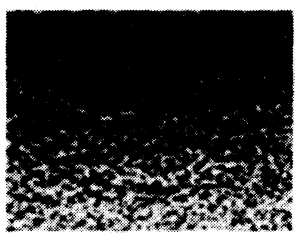

2.7
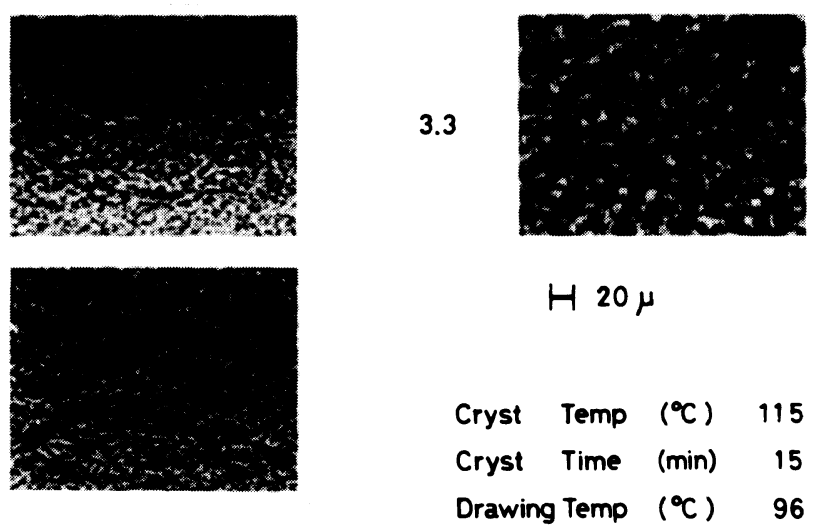

Figure 5. The polarized optical microscope pictures for different draw ratios.

tures higher than $120^{\circ} \mathrm{C}$, the transmittance is very low at low strains, but it increases with increasing strain and attains to $50-70 \%$ at $300 \%$ of strain. For films crystallized at the intermediate temperatures, the transmittance is relatively low at small strain and it decreases with increasing strain.

The $H_{\mathrm{v}}$-light scattering patterns were taken at different levels of elongation strain. For films having high degrees of crystallinities, the higher the level of elongation, the more the four leaf clover pattern skewed. For films having very low crystallinity, such an examination could not be carried out, because there was no light scattering from the films. On the other hand, for films which have intermediate degrees of crystallinities and on which a rough surface was developed by drawing, the four leaf clover pattern remained unchanged for all strain levels. 

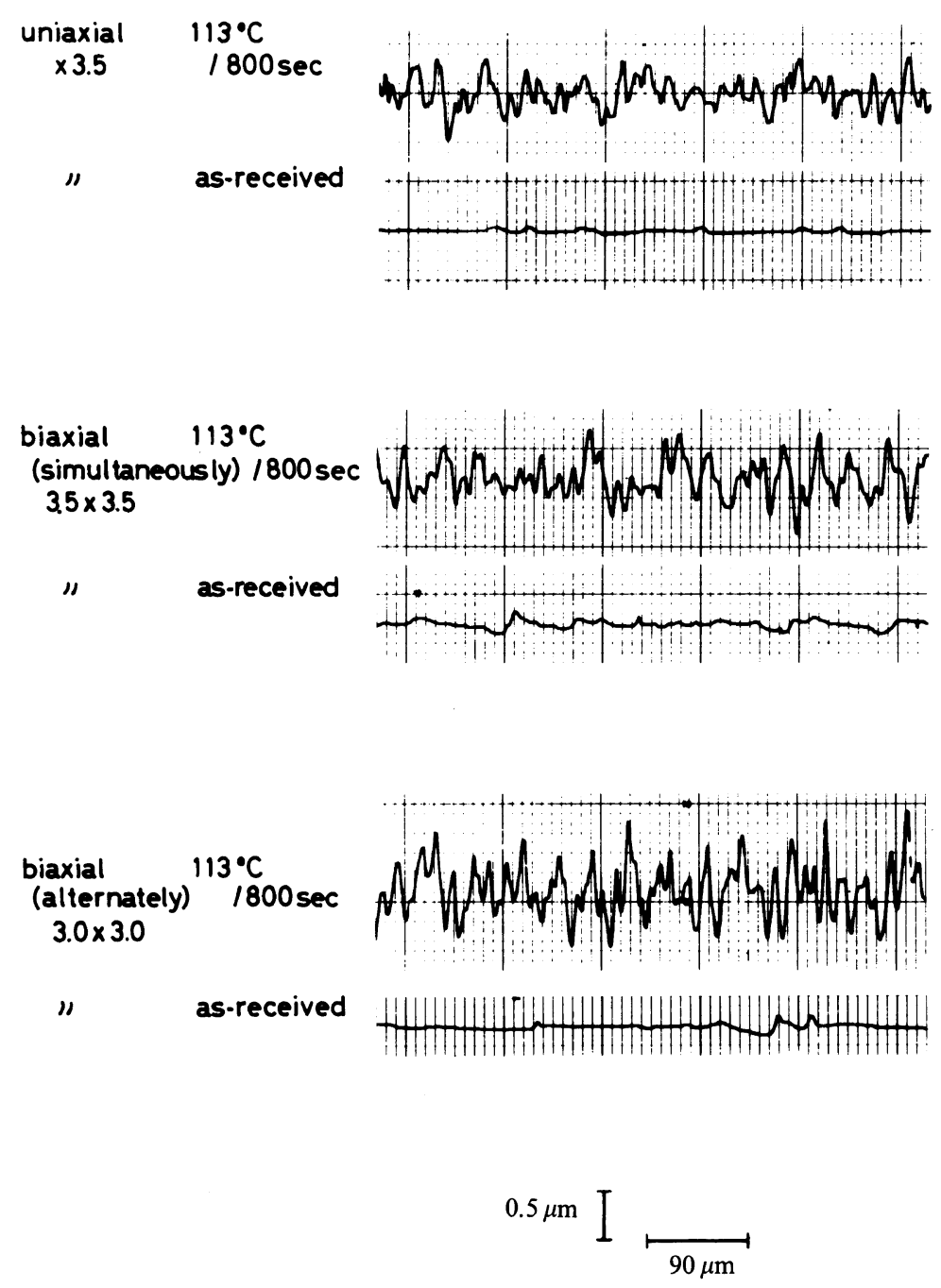

Figure 6. Surface texture and contour measurements for PET films by Surfcom-300A. The scan was carried out in the machine direction at a speed of $0.03 \mathrm{~mm} \mathrm{~s}^{-1}$.

POM pictures for films on which a rough surface was developed were taken at different levels of elongation, and are shown in Figure 5. The figure suggests that the spherulites separate from each other more and more by drawing. But the spherulites themselves do not deform. The separation of spherulites is not uniform. The nonuniform separation may produce different sizes of lumps between 10 and $20 \mu \mathrm{m}$ in diameter.

These defomation processes were also sug- gested from the nonlinear dynamic viscoelastic properties as reported previously. ${ }^{1}$ The dynamic viscoelastic and optical properties for the films having very low crystallinity and high crystallinity showed nonlinearity, while those for films having an intermediate crystallinity had a very linear feature. The nonlinearity for films having very low crystallinity is explained by the fact that amorphous chains slip past one another because of no crosslinking point. The nonlinearity for films having high crystallinity 
is caused by the disruption of the spherulitic structure. On the other hand, the linearity for films having an intermediate crystallinity is due to the fact that there is only one mechanism, that is, the orientation of amorphous chains which is very linear. In this case, the crystallites play a role of crosslinking but do not deform themselves. This is due to the appropriate size and number of spherulites in a specimen.

\section{Measurements of Roughness}

The roughness of films were measured by Surfcom-300A and some of the results are shown in Figure 6. As is obvious from the two top scans in the figure, the roughness develops on films prepared by crystallization at $113^{\circ} \mathrm{C}$ for $800 \mathrm{~s}$, followed by uniaxial drawing at $96^{\circ} \mathrm{C}$. Lumps have a depth of $0.2-1.0 \mu \mathrm{m}$ and size of $10-20 \mu \mathrm{m}$. The size of the lumps is very close to that estimated from the POM picture. From the $H_{\mathrm{v}}$-light scattering pattern, the spherulitic size in terms of diameter was estimated to be about $4 \mu \mathrm{m}$ using the method by Stein and Rhodes. ${ }^{9}$ Consequently, it is found that a lump consists of several spherulites.

It was also found that a rough surface developed in the cases of both simultaneous and alternate biaxial drawing. The condition for the development of a rough surface in the case of biaxial drawing was quite the same as that in the case of uniaxial drawing. The development is demonstrated in four scans in Figure 6. The development of a rough surface by biaxial drawing was also observed by SEM. The SEM picture exhibits undulation (see Figure 1(f)). In the case of biaxial drawing, it was confirmed by the $H_{\mathrm{v}}$-light scattering patterns that the origin of a rough surface is lumps of undeformed spherulites. On opaque PET films with rough surface, one can draw with pencil and with ink, but one cannot draw on transparent PET films with smooth surfaces.

\section{REFERENCES}

1. T. Amano and T. Seto, Polym. J., 5, 72 (1973).

2. A. Misra and R. S. Stein, J. Polym. Sci., Polym. Phys. Ed., 17, 235 (1979).

3. V. B. Gupta and S. Kumar, J. Appl. Polym. Sci., 26. 1885 (1981).

4. V. B. Gupta, C. Ramesh, and H. W. Siesler, J Polym. Sci., Polym. Phys. Ed., 23, 405 (1985).

5. A. B. Thompson and D. W. Woods, Trans. Faraday Soc., 52, 1383 (1956).

6. T. Kawaguchi, J. Polym. Sci., 32, 417 (1958).

7. J. E. Spruiell, D. E. McCord, and R. A. Beuerlein, Trans. Soc. Rheol., 16, 535 (1972).

8. A. Tanaka, H. Nagano, M. Shinohara, and S. Onogi, Polym. J., 20, 987 (1988).

9. R. S. Stein and M. B. Rhodes, J. Appl. Phys., 31, 1873 (1960). 